\section{Estudo \\ cobebate}

em Crestão

Planejamento
Revista Estudo \& Debate, Lajeado, v. 26, n. 3, 2019. ISSN 1983-036X

DOI: http://dx.doi.org/10.22410/issn.1983-036X.v26i3a2019.2093

\title{
DISPARIDADES LOCACIONAIS NA ESTRUTURA PRODUTIVA E FRAGMENTAÇÃO TERRITORIAL: UMA ANÁLISE DAS MESORREGIÓES DO RIO GRANDE DO NORTE
}

\author{
Denis Fernandes Alves ${ }^{1}$, Francisco do O’ de Lima Júnior ${ }^{2}$, \\ William Eufrásio Nunes Pereira ${ }^{3}$
}

\begin{abstract}
Resumo: O presente trabalho objetiva estudar o processo de diferenciaçôes na estrutura produtiva territorial desdobrado das desigualdades entre as Mesorregiōes do Estado do Rio Grande do Norte. Utilizou-se abordagem teórico-quantitativa com o calculo medidas de indicadores de estudos regionais (participação relativa, quociente locacional, coeficiente de localização, coeficiente de especializaçáo e coeficiente de reestruturaçáo), contextualizadas à revisão de literatura acerca de estudos sobre dinâmicas econômicas regionais e suas particularidades no caso brasileiro. Os dados foram da RAIS/MTE. Observou-se especializaçáo e diversificaçáo de algumas Mesorregiōes a partir de sua inserção competitiva na macro dinâmica econômica, destacandose: Agropecuária no Agreste Potiguar, Comércio na Mesorregião Central Potiguar e maior participação da Construção Civil no Leste Potiguar.
\end{abstract}

Palavras-chave: Fragmentação Territorial; Mesorregiōes Potiguares; Coeficientes de Especialização e de Localização.

1 Mestrando em Economia pelo Programa de Pós-Graduação em Economia da Universidade Federal do Rio Grande do Norte (PPGECO/UFRN); Graduado em Economia pela URCA; Pesquisador de Grupo de Estudos em Territorialidades Econômicas e Desenvolvimento Regional e Urbano (GETEDRU/DE-URCA) e do Grupo de Estudos e Pesquisas em Espaço, Trabalho, Inovação e Sustentabilidade (GEPETIS). E-mail: denis_fernandes@outlook.com

2 Professor Associado do Departamento de Economia da URCA, Crato/CE; Professor do Programa de Pósgraduação em Dinâmicas Territoriais do Semiárido (PLANDITES/UERN, Campus Pau dos Ferros/RN) Pesquisador do GETEDRU. E-mail: lima.junior@urca.br

3 Professor Adjunto do Departamento de Economia da UFRN; Professor do PPGECO/UFRN; Pesquisador do GEPETIS. E-mail: wenpereira2014@gmail.com 


\title{
LOCAL DISASTERS IN THE PRODUCTION STRUCTURE AND TERRITORIAL FRAGMENTATION: AN ANALYSIS OF THE MESORREGIÓES OF RIO GRANDE DO NORTE
}

\begin{abstract}
The present work aims to study the process of differentiation in the territorial productive structure deployed from the inequalities between the Mesoregions of the State of Rio Grande do Norte. A theoreticalquantitative approach was used to calculate the measures of regional studies indicators (relative participation, locational quotient, location coefficient, specialization coefficient and restructuring coefficient), contextualized to the literature review about regional economic dynamics studies and their particularities in the Brazilian case. Data were from RAIS / MTE. It was observed specialization and diversification of some Meso-regions based on their competitive insertion in the macro economic dynamics, especially: Agriculture in the Agreste Potiguar, Trade in the Central Potiguar Meso-region and greater participation of the Civil Construction in the East Potiguar.
\end{abstract}

Keywords: Territorial Fragmentation; Meso-Regions Potiguares; Specialization and Location Coefficients.

\section{INTRODUÇÃO}

Pensar a questão regional é entender que há a necessidade de superar as disparidades reproduzidas no território, sob diversas óticas, sejam elas intra ou inter-regionais. Nesse sentido, e dado a questão da concentração em determinadas regióes frente a outras o que gera tais gargalos, compreende-se que a questão regional é intrínseca de problemas econômicos, sociais e políticos, isto é, são as vertentes de um ciclo vicioso de subdesenvolvimento, como denomina Celso Furtado (2000). Enquanto existir um padrão espacial centrado no desequilíbrio territorial polarizado e desigual das atividades econômicas, por sua vez, acarretará na geração de efeitos regressivos da chamada causação circular cumulativa, teoria desenvolvida por Myrdal (1968), em que um processo acumulativo, quando não controlado, promoverá desigualdades crescentes.

A Ciência Regional, nesse aspecto, objetiva investigar as causas da riqueza regional e os motivos inerentes à formação do espaço econômico a partir das açóes de aglomeraçóes de atividades produtivas (PERROUX, 1950; MYRDAL, 1968; BOUDEVILLE, 1961; ISARD, 1962; NORTH, 1977; BREITBACH, 1988; BENKO, 1999). Nesse sentido, diversas são as teorias que embasam a dinâmica de desempenho econômico e as causas da sua disparidade no espaço regional. Segundo Breitbach (1988), dentro desse enfoque estão situadas a famosa Escola Alemã e a Escola Francesa, e ainda a Teoria da Base Econômica de Exportação, fundamentada por North (1977). Nesse sentido, é importante distinguir as teorias do desempenho econômico exógeno e endógeno, analise explorada mais à frente.

Aplicação dessas teorias mencionadas na atualidade é destaque em importantes trabalhos de cunho da Ciência Regional. No Brasil, estudos aplicados de métodos de análise regionais tem como precursores os estudos de Lodder (1974) e Haddad (1989). No caso da região Nordeste e, mais especificamente, do estado do Rio Grande do Norte versão artigos que abrangem abordagens mais específicas, explorando setores específicos e, por vezes, com recortes territoriais distintos, conforme pode ser visto no trabalho de Lima, Silva e Lima (2017), em que este explora sob a ótica mesorregional a estrutura industrial do RN. 
Desta forma, e a utilizar este recorte espacial, tem-se que a divisão territorial do RN, apresenta quatro mesorregiốes geográficas, a saber: Central Potiguar, Leste Potiguar, Agreste Potiguar e Oeste Potiguar. No presente artigo o objetivo é analisar a dinâmica da estrutura produtiva nas mesorregióes do $\mathrm{RN}$. Como se comporta os cinco grandes setores nos anos de 2007 e 2017. A hipótese é notar como a estrutura produtiva é reflexo do processo de desenvolvimento do território, identificando possíveis disparidades e similaridades entre as mesorregióes potiguares.

Com base nisso, entender a regiâo sob o aspecto socioeconômico auxilia no processo de diferenciaçấo regional-territorial-espacial presente no estado e como a atividade econômica produz e reproduz no espaço. Com o fito de alcançar os objetivos propostos, adota-se algumas medidas de análise regional como: medidas de localização e especialização, bem como a representatividade das atividades nas mesorregióes, por meio da participação relativa, e para analisar a configuração produtiva destas regiōes no Rio Grande do Norte. A justifica deste estudo é baseada pela relevância de se compreender como os grandes setores impactam na distribuição das atividades no contexto inter-mesorregional.

Portanto, o artigo está estruturado, além desta introduçáo e das consideraçóes finais, por outras três seções. A segunda seção discute a gênese da economia regional. Na terceira seção é explanado os procedimentos metodológicos utilizados, seguido, na quarta seção, pelos resultados e discussão da pesquisa.

\section{REVISÃO DE LITERATURA}

\subsection{A Gênese da Economia Regional e do desempenho econômico regional: endógeno e exógeno}

Desde os seus primórdios, a Ciência Regional ou economia regional, segundo Benko (1999) enquanto disciplina, trata do estudo atento e paciente dos problemas sociais nas suas dimensôes regionais ou espaciais, empregando diversas combinaçóes de investigação analítica e empírica. Considerado o pai da Economia Regional, Walter Isard publica, em 1975, sua obra Introduction to Regional Science, em que apresenta uma definição empírica de uma abordagem pluridisciplinar para um objeto regional cuja única especificidade é corresponder ao quadro de percepçáo de um problema social. O que segundo Benko (1999) esta nova ciência justifica-se pelo fato de a região acabar por ser a sede de problemas que é imperativo resolver.

Ao investigar as causas da riqueza regional e os motivos inerentes à formaçáo do espaço econômico a partir das açôes de aglomeraçôes de atividades produtivas, conforme os estudos de Perroux (1950), Myrdal (1960), Boudeville (1961) e Isard (1962), temse em consideraçáo importantes teorias nesse espectro. Segundo Pereira (2016) devido, possivelmente, à influência marshalliana, as teorias neoclássicas tradicionais reconheciam o papel das economias de aglomeraçáo como fator de indução da localização das firmas, mas esse papel era sempre secundário frente aos demais indutores do processo de localização, principalmente ao fator custo dos transportes. 
Nesse sentido, diversas são as teorias que embasam a dinâmica de desempenho econômico e as causas da sua disparidade no espaço regional. Segundo Breitbach (1988), dentro desse enfoque estão situadas a chamada Escola Alemã - composta pelos autores Von Thünen, Losch e Christaller ${ }^{4}$-, a Escola Francesa - com Perroux e Boudeville -, e ainda a Teoria da Base Econômica de Exportaçáo, fundamentada por North (1977). Nesse sentido, há teorias de desempenho econômico regional tanto do ponto de vista exógeno quanto endógeno. As teorias do desempenho econômico exógeno, são caracterizadas pela teoria dos Pólos de Crescimento proposta por Perroux (1964), a teoria de Causaçáo Circular Cumulativa desenvolvida por Myrdal (1965), e, a teoria de Base da Exportação elaborada por North (1977). Já a teoria relacionada ao crescimento endógeno mostra fatores vocacionados internos para alcançar o desempenho econômico (LUCAS, 1988; ROMER, 1990).

A análise do desempenho econômico regional passou a ter maior formalidade a partir da década de 1950, quando participa da chamada ciência regional, sistematizada inicialmente por Walter Isard nesta mesma década, sobretudo a partir dos estudos de Perroux (1964), Myrdal (1965) e North (1977), dentre os quais consideravam que este desempenho ocorreria a partir de um processo exógeno. No contexto regional, é através dos fatores exógenos que se estabelecem vantagens ou desvantagens, os quais promovem um fluxo contínuo do capital, tornando-se o principal no processo de acumulação ou estagnação regional (BREITBACH, 1988; LIMA, SIMÓES, 2009; PIACENTI; LIMA, 2017).

Nesse sentido, a primeira teoria, a de Pólos de Crescimento foi fundamentada por Perroux e afirma que o desempenho econômico ocorre a partir de um local caracterizado como enclave, que se destaca das demais localidades contíguas, aonde, a partir da instalaçáo ou existência de uma indústria considerada como chave ou "motriz", ocorre uma série de encadeamentos produtivos direcionados aos demais setores econômicos daquele conjunto econômico mesorregional (PERROUX, 1964).

Quanto às disparidades econômicas regionais, Myrdal (1965) ressaltou que este problema é consequência da concentração da atividade produtiva ${ }^{5}$, que em determinadas regióes se fortalecem, causando um efeito multiplicador do crescimento econômico, chegando ao conceito do princípio da causação circular cumulativa ou progressiva, também

4 Segundo Benko (1999), Chistaller é o fundador da teoria da localização das atividades terciárias.

5 Normalmente atividades do setor secundário. 
denominado princípio da cumulatividade, o qual gera efeitos positivos ou negativos no processo de desenvolvimento de uma determinada regiāo ${ }^{6}$.

E, por último, a Teoria de Base da Exportação possui como fundamento o comércio exterior e tem por princípio específico que o desempenho econômico local e regional é função dos seus produtos de base exportadora. North (1977) afirma que quando essa produçấo ocorre por meio de um processo dinâmico, gerando maior especialização em seu setor produtivo, fornece uma vantagem competitiva, gerando um excedente econômico capaz de induzir o desempenho das atividades não básicas de caráter local ou regional, denominadas como complementares a atividade base as quais são direcionadas ao mercado local, dinamizando o desempenho econômico regional (SCHWARTZMAN, 1977).

No caso da teoria do desempenho econômico endógeno, a qual emergiu a partir dos anos de 1980, destacam-se os fatores internos regionais, os quais, quando integrados de modo conjunto e dinâmico, impactam sobre o processo de desenvolvimento. Essa teoria foi amplamente difundida por meio dos estudos de Lucas (1988) e Romer (1990) como meio alternativo às críticas de modelos neoclássicos de crescimento econômico que conjecturava que as mudanças tecnológicas eram determinadas de forma exógena, levando à conclusão pessimista que políticas de governo e mercado nada podiam fazer para aumentar o crescimento econômico no longo prazo 7 .

\subsection{Espaço, Território e Regiáo: conceitos e discussão}

No que tange aos aspectos conceituais da ciência regional, é importante ressaltar a interdisciplinaridade dos conceitos de espaço, território e regiáo e como isto afeta os estudos sobre a economia regional e o desenvolvimento de um determinado território sobre o ponto de vista econômico.

Segundo Alentejando (2000, p.10) em termos geográficos a ideia de espaço "é visto como geometria, um conjunto de pontos e distâncias [...], uma noção", como na teoria

6 Esse processo de concentração de forças em determinadas regiôes, ocasiona dois efeitos: o regressivo (backwash effects) em que mesmo havendo progresso, produção e riqueza em determinadas regiōes, fazendo com que haja uma espécie de canalização de recursos para estas regiōes, as quais normalmente ocorrem em detrimento das regiôes menos desenvolvidas, mantendo um processo contínuo de desequilíbrio econômico regional; e o efeito propulsor (spread effects), segundo o qual uma atividade industrial instalada em determinada região pode gerar um efeito multiplicador às demais regióes em sua proximidade, uma espécie de transbordamento, uma vez que demandarão produtos de outros setores como o setor agrícola ou setor de serviços para fomentar a própria atividade industrial, estimulando o progresso técnico e, por consequência, o desempenho econômico regional. Caso o spread effects for capaz de neutralizar o backwash effects será, assim, estimulado o progresso da região; caso contrário, eles serão mantidos, causando a continuidade da disparidade econômica regional (MYRDAL, 1965).

7 A teoria do crescimento endógeno sugere que a mudança tecnológica é uma resposta aos incentivos econômicos no mercado que podem ser criadas e/ou afetados pelas instituiçóes do governo ou do setor privado e que as diferenças no crescimento econômico e a qualidade de vida entre regióes desenvolvidas e em desenvolvimento refere-se à adoção da tecnologia como exógena e livremente disponível para todos. Assim, a diferença entre os padróes de vida está no fato de que as regióes têm significativamente menos capital e menor taxa de retorno de investimento adicional. 
dos anéis concêntricos de Von Thünen, na hierarquia de lugares centrais a famosa teoria de Christaller ou, bem como na teoria da localização de Weber. O que difere da ideia da Áurea Breitbach (1988), quando esta enfatiza a relação entre região e espaço, e concede a ideia de espaço como, segundo a noção empírica, algo já dado como existente e também a imagem de que o espaço é necessariamente social ${ }^{8}$.

Ainda nesse campo, do ponto de vista marxista, Gotidiener (1993) faz menção ao debato iniciado entre Castells e Lefebvre, sobre a teoria do espaço. Para Castells o espaço é um produto material de uma dada formação social, essa ênfase estrutura a abordagem marxista sobre espaço, enquanto Lefebvre afirma que a "práxis espacial" é elevada a uma atividade radial ao lado de esforços para reorganizar as relaçôes sociais e ele sustenta tal perspectiva com uma teoria marxista de espaçoso.

Na discussão sobre território como categoria geográfica, Raffestin (1993) e Alentejano (2000) conceituam e corroboram, muito embora sejam múltiplas definiçōes, na ideia de território como um espaço onde se projetou um trabalho. Seja energia e informação, e que, por consequência, revela relaçóes marcadas pelo poder'. Vale ressaltar que o espaço é anterior ao território. E o território se forma a partir do espaço, sob uma açáo conduzida de um ator, em qualquer nível, cujo este "territorializa" o espaço (RAFFESTIN, 1993).

No que concerne ao termo região, há duas direçôes diferentes de conceituação da regiâo: uma primeira enfatizando a identidade; outra dando importância a diferença. $\mathrm{O}$ autor considera uma nova e profícua reconceituação da regiāo terá que passar necessariamente pela superação desta falsa oposição. Outro ponto importante é que há um debate entre dois caminhos: i) a busca de um novo conceito de região, incorporando as novas formulaçóes do campo das ciências econômicas e sociais; ii) a busca de conceitos alternativos ao de regiấo, entre os quais destaca-se a noção de lugar e a associaçáo local/global via redes (ALENTEJANO, 2000).

A ciência regional é inseparável do conceito de região. A região passa a ser vista como um produto real. De início, passa-se gradualmente da noçáo de regiâo natural à noçáo de região econômica, assistindo-se em seguida a uma renovação de ideias sob a inspiração dos economistas espaciais e com o impulso da "nova geografia", com fito de explicar os fenômenos regionais. Construído dentro de um quadro de solidariedade territorial. Refuta-se, assim, a regionalização e a análise regional, como classificação a partir de critérios externos a vida regional. Para compreender a regiáo é preciso viver a regiâo, e entender região enquanto categoria do espaço (BREITBACH, 1988; BENKO, 1999; ALENTEJANTO, 2000).

\section{PROCEDIMENTO METODOLÓGICO}

Com o objetivo de analisar a dinâmica da estrutura produtiva nas mesorregióes do RN. Como se comporta os cinco grandes setores nos anos de 2007 e 2017, tendo como base

8 Havendo, de acordo com Breitbach (1988), uma diferença entre espaço construído e espaço natural (alheio a qualquer pratica social).

9 Para Raffestin (1993) o espaço é a "prisão original" e o território é a prisão que os homens constroem para si. 
a dinâmica do emprego formal nestes respectivos setores, o artigo utiliza dados de origem secundária, provenientes da Relação Anual de Informações Sociais (RAIS), do Ministério do Trabalho e do Emprego (MTE) que é a principal fonte de informaçóes sobre emprego formal. O recorte temporal compreende os anos de 2007 e 2017. Sáo cinco os setores em observação utilizados. Contemplam as seguintes atividades produtivas: i) Indústria; ii) Construção Civil; iii) Comércio; iv) Serviços e; v) Agropecuária.

No procedimento metodológico adotado, foram computadas seis medidas de estudos regionais aplicados, a saber: participação relativa, quociente locacional, coeficiente de localização, coeficiente de especialização e coeficiente de reestruturação. Tais indicadores foram calculados inicialmente por Lodder (1974), Haddad (1989), Silva (2002), Lamarche et al. (2003), Ferreira de Lima (2003) e, posteriormente, em outros trabalhos como Silva Filho, Silva e Queiroz (2015), Piacenti e Lima (2017), Castro, Kuhn e Pena (2017), dentre outros. Deste modo, são utilizadas informaçóes de trabalhadores formais dos oito setores mencionados nas mesorregióes do Rio Grande do Norte nos anos selecionados. Paralelamente a participação relativa, os demais indicadores foram agrupados em medidas de localização e medidas de especialização.

Assim, após escolhidas as variáveis de análise devem-se levar em conta as seguintes definiçôes: $P O_{i j}=$ pessoas ocupadas, no setor i da região j; $P O_{t i}=$ total de pessoas ocupadas, na região j; $P O_{i t}=$ pessoas ocupadas, do setor i na região de referência; $P O_{t t}=$ total de

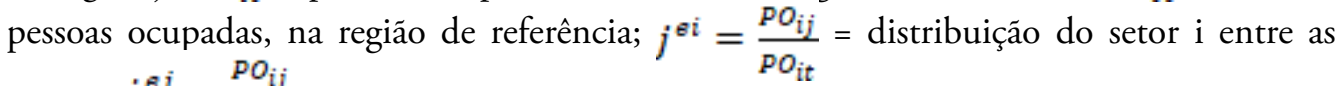
regiōes; $i^{e j}=\frac{P O_{i j}}{P O_{t j}}=$ distribuição i na região j, ou seja, mostra a participação de cada setor na estrutura produtiva de cada mesorregião; $T 0=$ ano inicial; $T 1=$ ano final.

\subsection{Participação Relativa}

O primeiro indicador proposto no estudo é a Participação Relativa $(P R)$ da atividade em relação ao total de atividade na mesorregiâo ao total de atividades no RN. Este índice leva em consideração a seguinte expressão:

$$
P R=P O_{i j} / P O_{i t}
$$

Este indicador varia entre 0 e 1 , a interpretação é a de que quanto mais próximo de um maior será a importância de determinada atividade terá em relação ao estado como um todo (CASTRO; KUHN; PENA, 2017).

A seguir serão enfatizadas as medidas de localização e de especialização utilizadas.

\subsection{Medidas de Localização}

\subsubsection{Quociente Locacional}

Como primeiro indicador proposto na medida de localização está o Quociente Locacional $(Q L)$, embora muito utilizado por diversos pesquisadores, inclusive muito recomendado por Isard (1972) e North (1977, p. 301) quando se almeja mostrar o 
comportamento locacional dos ramos de atividades, sobretudo quando se trata do setor secundário nas diferentes regiōes, comparando com uma macrorregião de referência conforme Haddad (1989), Costa (2002), Castro, Kuhn e Pena (2017) e Piacenti e Lima (2017). A expressão para o cálculo do QL é a seguinte:

$$
Q L=\frac{P O_{i j} / P O_{i t}}{P O_{t j} / P O_{t t}}
$$

Dessa forma, o $Q L$ compara à participação percentual dos trabalhadores formais devidamente empregados, de uma regiáo $j$ com a participaçáo percentual da regiáo de referência, no caso o estado do Rio Grande do Norte. Segundo Piacenti e Lima (2017) o indicador informa quantas vezes o setor $i$ é mais (ou menos) importante, ou especializado, para a região $j$ vis-à-vis a macrorregião de referência. Deste modo, a importância da regiáo $j$ no contexto macrorregional, em relaçáo ao setor estudado, é demonstrada quando o QL assume valores acima de 1 . Nesses casos o setor será considerado especializado. O contrário acontece quando o $Q L$ for menor que 1 . Não sendo especializado em determinado setor.

\subsubsection{Coeficiente de Localizaçáo}

A segunda medida de localização apresentada é o Coeficiente de Localização (CLoc), que se dá ao evidenciar a influência de determinado setor em relação a sua distribuição de trabalhadores formais empregados numa mesorregiāo, considerando-se a mão de obra total de todo o RN (SILVA FILHO; SILVA; QUEIROZ, 2015). A fórmula utilizada para o cálculo é a seguinte:

$$
C L O C=\left\lceil\frac{\left|j^{e i}-\sum_{i} j^{e i}\right|}{2}\right\rceil
$$

Deste modo, esse coeficiente varia entre 0 e 1 e permite identificar o grau de dispersão relativa das atividades econômicas e selecionar aquelas que, teriam menor tendência à concentração espacial. Ou seja, valores próximos a um tem-se concentração enquanto valores próximos a 0 observa-se dispersão das atividades produtivas conforme explicado por Haddad (1989) e mais recentemente por Castro, Kuhn e Pena (2017) e Piacenti e Lima (2017) em suas pesquisas.

\subsection{3 Índice de Hirschman-Herfindahl (IHH)}

Por último, dentre as medidas de localização, tem-se o IHH, uma das medidas mais difundidas nos estudos de economia regional, conforme Haddad (1989), Simões (2005) e Piacenti e Lima (2017). O propósito é destacar qual é a concentração de um determinado setor na regiáo $\mathrm{j}$ comparando a mesma a uma regiâo maior. Basicamente o IHH é a divisão da participaçáo do setor $i$ da região $j$ sobre o total do setor $i$ da região de referência, com a participaçấo do total da regiáo $j$ sobre o total da regiáo de referência. Seguindo determinada expressão, a saber: 


$$
I H H=\left({ }^{P O_{i j}} / P_{t i}\right)-\left(P O_{i t} / P O_{t t}\right)
$$

Isso acontece, por existirem atividades que possuem uma capacidade maior de concentração e com um poder de atração de outras atividades maior, devido ao seu perfil produtivo, maiores detalhes ver Noce et al. (2005).

Neste sentido, quando o IHH apresentar um valor positivo indica que o setor $i \mathrm{da}$ região $j$ está mais concentrado, exercendo um poder de atração maior, dado sua especialização. Valores negativos indicam um baixo poder de atração em comparação a região de referência (CASTRO; KUHN; PENA, 2017; PIACENTI; LIMA, 2017).

\subsection{Medidas de Especializaçáo}

Dentre as medidas de especialização adotadas, e conforme Paiva (2004) e Piacenti e Lima (2017) a especialização além de ser a manifestação da determinação primeira de "potencial", ela é a "capacidade mobilizatória" de um determinado setor, ou seja, o poder de "multiplicação" (no espaço e no tempo) do fomento ao mesmo. Nesse sentido, foram utilizadas duas medidas, quais sejam: Coeficiente de Especialização $\left(C E s p_{i}\right)$ e o Coeficiente de Reestruturação $\left(\right.$ CRest $\left._{j}\right)$.

\subsubsection{Coeficiente de Especializaçáo}

O CEsp $p_{i}$ tem como objetivo comprar a estrutura produtiva de uma região $j$ com a estrutura produtiva do estado como um todo. Deste modo, a regiáo que possuir uma estrutura produtiva mais diferenciada em relação com a regiāo de diferença será especializada. Para o cálculo, tem-se a seguinte fórmula:

$$
\operatorname{CEsp}_{i}=\sum_{i}\left[\frac{\left|i^{e i}-\sum_{j} i^{\epsilon j}\right|}{2}\right]
$$

Este coeficiente varia entre 0 e 1 , e quanto mais próximo de zero a regiáo apresentará uma estrutura produtiva similar ao da região de referência. Caso contrário será especializada, pois apresentará um grau de especialização em atividades diferentes ao do estado como um todo (COSTA, 2002; PIACENTI; LIMA, 2017).

\subsubsection{Coeficiente de Reestruturaçáo}

O Coeficiente de Restruturação ou CRest $_{i}$ mostra de maneira simples se houve alteraçáo na estrutura produtiva da regiáo $j$ durante um determinado período de tempo (T0 e T1). Assim, se a estrutura produtiva se alterou uma das explicaçóes será que a regiáo $j$ passou a se especializar em um determinado setor $i$. Para cômputo dessas informaçóes, utilizar-se-á seguinte formula:

$$
\text { CRest }_{j}=\sum_{i}\left[\frac{\left|\begin{array}{l}
T 0 \\
i^{e j}-T 1 \\
i^{e j}
\end{array}\right|}{2}\right]
$$


O CRest $_{j}$ varia entre 0 e 1 , e se próximo de zero não terá havido mudanças na composição setorial da região, e, quanto mais próximo de um as mudanças terão sido significativas (HADDAD, 1989; COSTA, 2002; PIACENTI; LIMA, 2017).

\section{RESULTADOS E DISCUSSÃO}

Esta seção propóe expor os resultados da pesquisa, o objetivo é estudar como se comportou os grandes setores da estrutura produtiva nas mesorregióes do RN utilizando métodos de análise regional.

É importante, antes da análise dos indicadores propostos, observar de maneira geral como o emprego formal no território potiguar está espacialmente estabelecido. Ainda é forte a concentração das atividades produtivas no litoral leste, onde está inserido a capital e outras grandes cidades como Macaíba, São Gonçalo do Amarante e Parnamirim. Diferentemente do que ocorre na mesorregião do Agreste e Central Potiguar.

A mesorregião do Oeste Potiguar se mostra em ascensão no setor empregatício, bem como há uma forte tendência ao crescimento dessa região e posteriormente desenvolvimento, como defendido por Rostow (1974) em que destaca cinco etapas para o processo de desenvolvimento econômico de uma regiâo. Muito embora, haja autores que discordem dessa visão etapista do desenvolvimento, como Celso Furtado (2000), em que este afirma que o subdesenvolvimento é um processo autônomo e não quer dizer uma etapa antes do eventual desenvolvimento.

Gráfico 01: Mão de obra formal total da estrutura produtiva por mesorregióes do RN 2007/2017

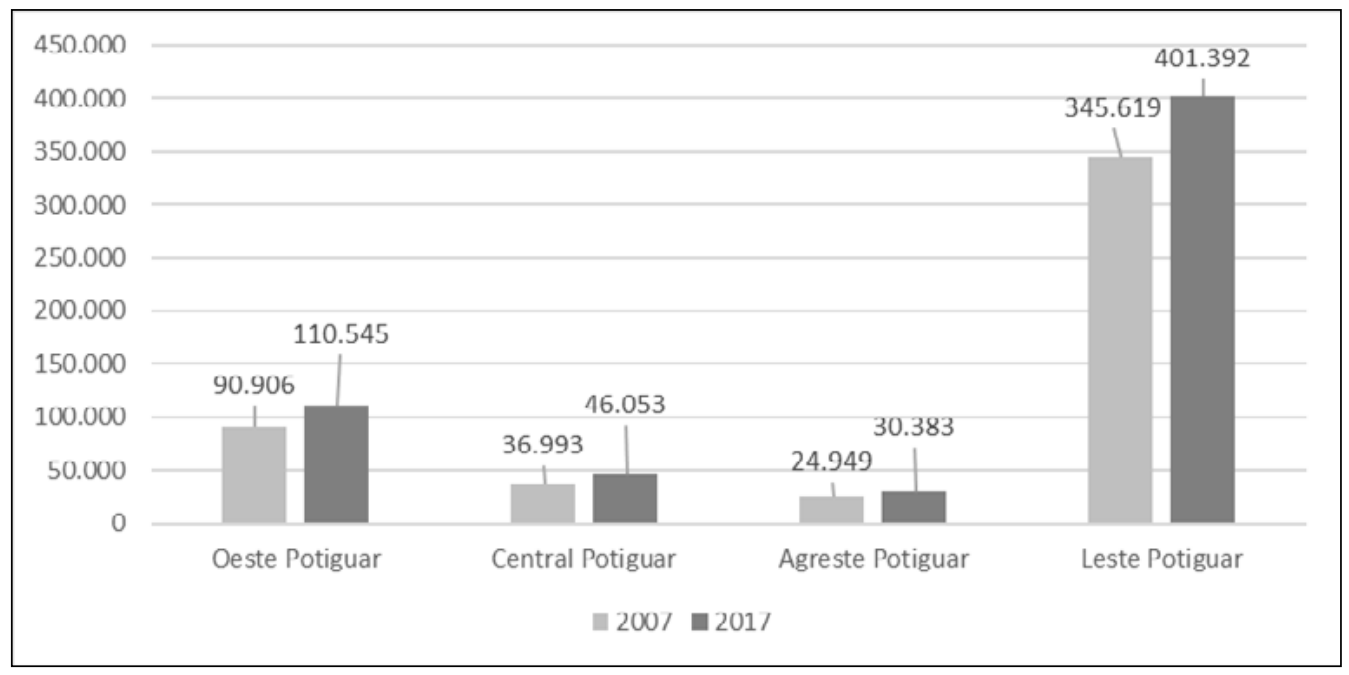

Fonte: elaboração própria a partir dos dados da RAIS/MTE.

De início, a Tabela 01 mostra a participação relativa da população ocupada por setor em cada uma das mesorregióes. Como este índice varia entre zero e um, destaca- 
se no intervalo de tempo estudado, o crescimento do emprego no setor de comércio em todas as mesorregiōes, sobretudo no Agreste Potiguar com uma variação percentual de aproximadamente $72,4 \%$. Outro dado importante é a queda expressiva no setor da construção civil, inclusive na mesorregião leste potiguar, onde se encontra na Regiáo Metropolitana de Natal, um processo de verticalização e urbanização nos últimos anos.

Tabela 01: Participação Relativa da Estrutura Produtiva por Mesorregióes do RN 2007/2017

\begin{tabular}{ccccc}
\hline $\begin{array}{c}\text { Grandes Setores } \\
\mathbf{2 0 0 7}\end{array}$ & Oeste Potiguar & Central Potiguar & Agreste Potiguar & Leste Potiguar \\
\hline Indústria & 0,166 & 0,220 & 0,108 & 0,157 \\
Construçáo Civil & 0,068 & 0,037 & 0,039 & 0,050 \\
Comércio & 0,170 & 0,158 & 0,101 & 0,168 \\
Serviços & 0,477 & 0,562 & 0,726 & 0,606 \\
Agropecuária & 0,119 & 0,023 & 0,026 & 0,020 \\
\hline Total & $\mathbf{1 , 0 0 0}$ & $\mathbf{1 , 0 0 0}$ & $\mathbf{1 , 0 0 0}$ & $\mathbf{1 , 0 0 0}$ \\
\hline Grandes Setores & Oeste Potiguar & Central Potiguar & Agreste Potiguar & Leste Potiguar \\
2017 & 0,129 & 0,228 & 0,076 & 0,109 \\
Indústria & 0,043 & 0,025 & 0,029 & 0,042 \\
Construçáo Civil & 0,212 & 0,206 & 0,174 & 0,189 \\
Comércio & 0,525 & 0,519 & 0,686 & 0,647 \\
Serviços & 0,091 & 0,022 & 0,034 & 0,014 \\
\hline Agropecuária & $\mathbf{1 , 0 0 0}$ & $\mathbf{1 , 0 0 0}$ & $\mathbf{1 , 0 0 0}$ & $\mathbf{1 , 0 0 0}$ \\
\hline Total &
\end{tabular}

Fonte: elaboração própria a partir dos dados da RAIS/MTE.

Referente as medidas de localização, o primeiro indicador exposto é o Quociente Locacional. Este indicador irá mostrar quais os setores mais especializados em determinadas regiốes frente a uma macrorregiáo de referência $(\mathrm{RN})$. Nesse sentido, conforme explicado anteriormente, acima de um, irá indicar que a região é especializada em determinado setor.

Nota-se que tem crescido nos últimos anos a especialização do Oeste Potiguar em quatro dos cinco grandes setores. Isso indica um expressivo processo de crescimento das cidades de pequeno e médio porte daquela mesorregião, destaca-se Mossoró, Pau dos Ferros mais ao Sul e Assú, mais próximo da mesorregião Central potiguar. Outro dado importante expresso na Tabela 02, é a especialização de setores, a saber: agropecuária no Agreste Potiguar; comércio na mesorregião Central Potiguar e; construçáo civil na mesorregião do Leste Potiguar. 
Tabela 02: Quociente Locacional da Estrutura Produtiva por Mesorregióes do RN 2007/2017

\begin{tabular}{ccccc}
\hline $\begin{array}{c}\text { Grandes Setores } \\
\mathbf{2 0 0 7}\end{array}$ & Oeste Potiguar & Central Potiguar & Agreste Potiguar & Leste Potiguar \\
\hline Indústria & $\mathbf{1 , 0 3 3}$ & $\mathbf{1 , 3 6 9}$ & 0,670 & 0,976 \\
Construçáo Civil & $\mathbf{1 , 3 2 7}$ & 0,725 & 0,762 & 0,961 \\
Comércio & $\mathbf{1 , 0 3 5}$ & 0,963 & 0,617 & $\mathbf{1 , 0 2 2}$ \\
Serviços & 0,814 & 0,960 & $\mathbf{1 , 2 4 0}$ & $\mathbf{1 , 0 3 6}$ \\
Agropecuária & $\mathbf{3 , 0 9 9}$ & 0,586 & 0,674 & 0,516 \\
\hline Total & $\mathbf{1 , 0 0 0}$ & $\mathbf{1 , 0 0 0}$ & $\mathbf{1 , 0 0 0}$ & $\mathbf{1 , 0 0 0}$ \\
\hline Grandes Setores & Oeste Potiguar & Central Potiguar & Agreste Potiguar & Leste Potiguar \\
2017 & $\mathbf{1 , 0 7 5}$ & $\mathbf{1 , 8 9 6}$ & 0,636 & 0,904 \\
\hline Indústria & $\mathbf{1 , 0 7 0}$ & 0,638 & 0,726 & $\mathbf{1 , 0 4 3}$ \\
Construção Civil & $\mathbf{1 , 0 9 5}$ & $\mathbf{1 , 0 6 4}$ & 0,899 & 0,974 \\
Comércio & 0,853 & 0,843 & $\mathbf{1 , 1 1 4}$ & $\mathbf{1 , 0 5 0}$ \\
Serviços & $\mathbf{2 , 9 8 6}$ & 0,712 & $\mathbf{1 , 1 3 4}$ & 0,476 \\
\hline Agropecuária & $\mathbf{1 , 0 0 0}$ & $\mathbf{1 , 0 0 0}$ & $\mathbf{1 , 0 0 0}$ & $\mathbf{1 , 0 0 0}$ \\
\hline Total & & &
\end{tabular}

Fonte: elaboração própria a partir dos dados da RAIS/MTE.

Outra medida de localização utilizada, é o coeficiente locacional. Que expressa e evidencia a influência de determinado setor em relaçáo aos trabalhadores formais empregados numa dada mesorregiáo, considerando-se a mão de obra total de todo o RN. Deste modo, conforme dito anteriormente, permite identificar o grau de dispersão relativa das atividades econômicas e selecionar aquelas que, teriam menor tendência à concentração espacial.

No intervalo de tempo utilizado, destacam-se alguns resultados expressivos. O primeiro dele seria a tendência a concentração do setor secundário no leste potiguar, onde detém das atividades de maior repercussão econômica. Vale destacar que, segundo Lima, Silva e Lima (2017) a indústria dinâmica apresenta uma tendência de forte concentração nas mesorregióes potiguares, exceto na Leste Potiguar. Dentre as atividades do setor cabe destaque para a indústria de produtos minerais não metálicos, principalmente pela cerâmica estrutural utilizada na construção civil, cimento, artefatos de concreto, mármores e granitos. Porém, há uma tendência crescente a concentração espacial desse setor nas mesorregióes do Oeste Potiguar e Central Potiguar, assim como os setores de Comércio e Serviços.

O segundo dado importante é referente a dispersão das atividades econômicas e produtivas na mesorregiáo do Agreste Potiguar, tendo em vista a distância locacional para o grande centro (Natal e região vizinha) muitas atividades se deslocam para tal mesorregião, prevalecendo nesta o setor de serviços. 
Tabela 03: Coeficiente Locacional da Estrutura Produtiva por Mesorregióes do RN 2007/2017

\begin{tabular}{ccccc}
\hline $\begin{array}{c}\text { Grandes Setores } \\
\mathbf{2 0 0 7}\end{array}$ & Oeste Potiguar & Central Potiguar & Agreste Potiguar & Leste Potiguar \\
\hline Indústria & 0,003 & 0,030 & 0,026 & 0,002 \\
Construção Civil & 0,008 & 0,007 & 0,006 & 0,001 \\
Comércio & 0,003 & 0,003 & 0,031 & 0,002 \\
Serviços & 0,054 & 0,012 & 0,070 & 0,010 \\
Agropecuária & 0,040 & 0,008 & 0,006 & 0,009 \\
\hline Grandes Setores & Oeste Potiguar & Central Potiguar & Agreste Potiguar & Leste Potiguar \\
2017 & 0,005 & 0,054 & 0,022 & 0,006 \\
Indústria & 0,001 & 0,007 & 0,005 & 0,001 \\
Construçáo Civil & 0,009 & 0,006 & 0,010 & 0,003 \\
Comércio & 0,045 & 0,048 & 0,035 & 0,015 \\
Serviços & 0,030 & 0,004 & 0,002 & 0,008 \\
Agropecuária & & & \\
\hline
\end{tabular}

Fonte: elaboração própria a partir dos dados da RAIS/MTE.

Por último, nas medidas de localização, fora obtido o difundido IHH expresso na Tabela 04 . O mesmo tem por objetivo destacar qual é a concentração de um determinado setor na região $j$ comparando a mesma a uma região maior. Nesse sentido, observa-se a concentração dos setores na mesorregião Oeste Potiguar, desse modo, exercendo um poder de atração maior, dado sua especialização, do que as demais mesorregióes em todos os setores, exceto serviços. Outros resultados importantes, é o aumento da atração dos setores de comércio na mesorregião Central Potiguar; agropecuária no Agreste Potiguar e a construção civil no Leste Potiguar. Indicando um processo de desenvolvimento polarizado por mesorregióes, corroborando com a teoria de Perroux (1977).

Tabela 04: Índice de Hirschman Herfindahl da Estrutura Produtiva por Mesorregióes do $\mathrm{RN}-2007 / 2017$

\begin{tabular}{ccccc}
\hline $\begin{array}{c}\text { Grandes Setores } \\
\mathbf{2 0 0 7}\end{array}$ & Oeste Potiguar & Central Potiguar & Agreste Potiguar & Leste Potiguar \\
\hline Indústria & $\mathbf{0 , 0 0 6}$ & $\mathbf{0 , 0 2 7}$ & $-0,016$ & $-0,017$ \\
Construção Civil & $\mathbf{0 , 0 6 0}$ & $-0,020$ & $-0,012$ & $-0,027$ \\
Comércio & $\mathbf{0 , 0 0 6}$ & $-0,003$ & $-0,019$ & $\mathbf{0 , 0 1 5}$ \\
Serviços & $-0,034$ & $-0,003$ & $\mathbf{0 , 0 1 2}$ & $\mathbf{0 , 0 2 5}$ \\
Agropecuária & $\mathbf{0 , 3 8 3}$ & $-0,031$ & $-0,016$ & $-0,336$ \\
\hline
\end{tabular}




\begin{tabular}{ccccc}
\hline $\begin{array}{c}\text { Grandes Setores } \\
\mathbf{2 0 1 7}\end{array}$ & Oeste Potiguar & Central Potiguar & Agreste Potiguar & Leste Potiguar \\
\hline Indústria & $\mathbf{0 , 0 1 4}$ & $\mathbf{0 , 0 7 0}$ & $-0,019$ & $-0,065$ \\
Construçáo Civil & $\mathbf{0 , 0 1 3}$ & $-0,028$ & $-0,014$ & $\mathbf{0 , 0 2 9}$ \\
Comércio & $\mathbf{0 , 0 1 8}$ & $\mathbf{0 , 0 0 5}$ & $-0,005$ & $-0,018$ \\
Serviços & $-0,028$ & $-0,012$ & $\mathbf{0 , 0 0 6}$ & $\mathbf{0 , 0 3 4}$ \\
Agropecuária & $\mathbf{0 , 3 7 3}$ & $-0,023$ & $\mathbf{0 , 0 0 7}$ & $-0,358$ \\
\hline
\end{tabular}

Fonte: elaboração própria a partir dos dados da RAIS/MTE.

São dois os indicadores referentes a especialização produtiva utilizados. Primeiramente, o coeficiente de especialização da estrutura produtiva, chama atenção para duas mesorregióes, a saber: Oeste Potiguar e Central Potiguar. No comportamento dos anos em análise, observa-se o aumento expressivo da especialização em comércio das mesorregióes Oeste Potiguar e Central Potiguar, com um aumento de aproximadamente $200 \%$ em relação a 2007 . Vale destacar que no setor de serviços houve um aumento da especialização e, consequentemente, do número de empregos formais em 500\% em relação a T0 (2007).

Tabela 05: Coeficiente de Especialização da Estrutura Produtiva por Mesorregióes do RN $-2007 / 2017$

\begin{tabular}{ccccc}
\hline $\begin{array}{c}\text { Grandes Setores } \\
\mathbf{2 0 0 7}\end{array}$ & Oeste Potiguar & Central Potiguar & Agreste Potiguar & Leste Potiguar \\
\hline Indústria & 0,003 & 0,014 & 0,008 & 0,008 \\
Construção Civil & 0,030 & 0,010 & 0,006 & 0,014 \\
Comércio & 0,003 & 0,001 & 0,010 & 0,008 \\
Serviços & 0,017 & 0,001 & 0,006 & 0,012 \\
Agropecuária & 0,191 & 0,015 & 0,008 & 0,168 \\
\hline Grandes Setores & Oeste Potiguar & Central Potiguar & Agreste Potiguar & Leste Potiguar \\
2017 & 0,007 & 0,035 & 0,009 & 0,033 \\
Indústria & 0,007 & 0,014 & 0,007 & 0,015 \\
Construção Civil & 0,009 & 0,003 & 0,003 & 0,009 \\
Comércio & 0,014 & 0,006 & 0,003 & 0,017 \\
Serviços & 0,187 & 0,011 & 0,003 & 0,179 \\
Agropecuária & & & \\
\hline
\end{tabular}

Fonte: elaboração própria a partir dos dados da RAIS/MTE.

Por último, mas não menos importante. Tem-se o coeficiente de reestruturação da estrutura produtiva. Este indicador irá demonstrar se a estrutura produtiva se alterou uma das explicaçóes será que a região $j$ passou a se especializar em um determinado setor $i$. 
Como mostra a Tabela 06, houveram mudanças na estrutura produtiva de todas as mesorregióes. Com destaque para as mesorregiôes do Oeste Potiguar e Central Potiguar, que passaram a se especializar em todos os setores, dado a sua localização e a polarizaçáo do crescimento e desenvolvimento do estado, nota-se um processo de interiorização das atividades produtivas, bem como um espraiamento dos setores antes concentrados no leste potiguar.

No entanto ainda é expressiva a mudança na estrutura produtiva do Leste Potiguar, sobretudo na indústria que tem uma forte concentração nesta região. Diferentemente do que ocorre no Agreste Potiguar que não se especializa no setor secundário e sim em atividades de menor impacto econômico, como comércio, serviços e agropecuária, conforme descrito este processo por Furtado (2000).

Tabela 06: Coeficiente de Restruturação da Estrutura Produtiva por Mesorregiōes do RN $-2007 / 2017$

\begin{tabular}{ccccc}
\hline $\begin{array}{c}\text { Grandes Setores } \\
\mathbf{2 0 0 7 / 2 0 1 7}\end{array}$ & Oeste Potiguar & Central Potiguar & Agreste Potiguar & Leste Potiguar \\
\hline Indústria & 0,007 & 0,023 & 0,000 & 0,030 \\
Construção Civil & 0,021 & 0,002 & 0,000 & 0,023 \\
Comércio & 0,008 & 0,006 & 0,008 & 0,022 \\
Serviços & 0,006 & 0,003 & 0,002 & 0,001 \\
Agropecuária & 0,002 & 0,006 & 0,012 & 0,016 \\
\hline
\end{tabular}

Fonte: elaboração própria a partir dos dados da RAIS/MTE.

\section{CONSIDERAÇÓES FINAIS}

As preocupaçóes com as desigualdades regionais foram retomadas com as açóes objetivando a inserção competitiva fazendo com que, na ausência de uma política nacional de desenvolvimento regional seguida com nitidez, diversos estados e regióes adotassem medidas compensando esta ausência dentre elas a atração de investimentos com uso de incentivos bem como se apegassem também ao ciclo de transformaçóes econômicas vivenciados pela economia brasileira de 2003 até 2014 .

Entretanto, dadas as condiçóes heterogêneas de nossa economia, permaneceram disparidades que desdobraram um processo de fragmentação territorial percebido em diversos indicadores econômicos. O presente ensaio buscou estudar este processo através do calculo de seis indicadores medidas regionais (de localização e de especialização) para as Mesorregióes do Rio Grande do Norte, com base em dados do banco de informaçóes RAIS do Ministério do Emprego e Trabalho.

Conforme atestado ao longo da análise dos Resultados e Discussóes, alcançando aos objetivos propostos, observou-se especialização e diversificação de algumas Mesorregióes a partir de sua inserçáo competitiva na macro dinâmica econômica, destacando-se: 
Agropecuária no Agreste Potiguar, Comércio na Mesorregião Central Potiguar e maior participação da Construção Civil no Leste Potiguar.

A atividade industrial ainda tem forte concentração na Mesorregião Leste Potiguar, devido ao fato de ser o principal parque manufatureiro do estado se localizando a Região Metropolitana de Natal. Porém, também verificou-se uma há uma tendência crescente de haver concentração desse setor nas mesorregióes do Oeste Potiguar e Central Potiguar decorrente da consolidação da industrial mineral e de minerais não-metálicos respectivamente. Isto também é observado para os setores de Comércio e Serviços mais associados aos movimentos econômicos do ciclo pós-2003, com foco em políticas transversais que indiretamente afetaram os serviços e o comercio.

Atesta-se a necessidade de retomada destes estudos tendo como suporte a elaboração de outros indicadores de medidas regionais para comparação e ampliação das notas conclusivas. Outro apontamento que requer a ampliação desta investigação é o próprio uso da base de dados RAIS. Sendo o Nordeste uma economia marcada pela presença da economia informal em todos os seus segmentos, este conjunto de dados só capta a formalidade dando, portanto um retrato menos amplo de sua dinâmica econômica.

\section{REFERÊNCIAS}

ALENTEJANO, P. R. R. Espaço, território e regiáo: uma tentativa de conceituaçáo. Texto para discussão (Programa de Pós-Graduação em Economia da UFF), Niterói, 2000.

BENKO, G. A ciência regional. Oeiras: Celta Editora, 1999.

BOUDEVILLE, J. R. Les Espaces Économiques. Paris: PUF, 1961.

BREITBACH, A.C.M. Estudo sobre o conceito de regiáo. FEE n. 13, 8/1988, Porto Alegre.

CASTRO, V. C.; KUHN, L.; PENA, H. W. A. Análise do quociente locacional e da dinâmica produtiva do município de Salinopólis - Pará. Revista Observatorio de la Economía Latinoamericana, Brasil, set. 2017. Disponível em: <http://www.eumed.net/ cursecon/ecolat/br/2017/quociente-locacional.html>. Acesso em 03 nov. 2018.

COSTA, J. S. (Coord.). Compêndio de Economia Regional. APDR. Coimbra: Gráfica de Coimbra Lda., Lisboa, APDR, 2002.

FERRERA DE LIMA, J.. A concepção do espaço econômico polarizado. Interaçôes:

Revista Internacional de Desenvolvimento Local, Campo Grande, v. 04, n. 07, p. 0713, 2003.

FURTADO, C. Teoria e Política do Desenvolvimento Econômico. Paz e Terra, SP, 10. ed. 2000 . 
GOTTDIENER, Mark. A produção social do espaço urbano. In: A produção social do espaço urbano. 1997. p. 77-158.

HADDAD, J. H. (Org.). Economia regional: teoria e métodos de análise. Fortaleza: BNB/ETIENE, 1989.

ISARD, W. Méthodes d'analyse régionale. Paris: Dunod, 1972.

LODDER, C. A. Padrōes locacionais e desenvolvimento regional. Revista Brasileira de Economia. Rio de Janeiro, v. 28, n. 01, p. 3-128, 1974.

LIMA, A. C. C.; SIMÕES, R. F. Teorias do desenvolvimento regional e suas implicaçóes de política econômica no pós-guerra: $\mathrm{O}$ caso do Brasil. Belo Horizonte: UFMG/Cedeplar, MG. 2009. Disponível em: <http://cedeplar.face.ufmg.br/pesquisas/td/ TD\%20358.pdf>. Acesso em: 10 mai. 2016.

LAMARCHE, R.; SRINATH, K. ; RAY, D. M. Correct partitioning of regional growth rates: Improvements in shift-share theory. Canadian Journal of Regional Science. Montréal, v. 36, n. 01, p.121-141, 2003

LIMA, E. P. C.; SILVA, A. C.; LIMA, E. C. Assimetrias locacionais e padrão industrial: Uma análise das Mesorregióes do Rio Grande do Norte. Revista Espacios, v. 38. n. 23. p. 36. 2017.

LUCAS, Robert E. Jr. On the Mechanics of Development Planning. Journal of Monetary Economics, New York, v. 22, n. 1(July), 1988. p. 3-42.

MYRDAL, G. Teoria Econômica e Regióes Subdesenvolvidas. Rio de Janeiro: SAGA, 2. ed. 1968.

NOCE, Rommel et al. Concentração das exportações no mercado internacional de madeira serrada. Revista Árvore, v. 29, n. 3, p. 431-437, 2005.

NORTH, D. C. Teoria da localização e crescimento econômico regional. In:

Schwartzman, J. Economia regional: textos escolhidos. Belo Horizonte: Cedeplar, 1977.

PEREIRA, W. E. N. Reestruturação do setor industrial de Campina Grande-PB a partir dos anos 1990 / William Eufrásio Nunes Pereira [recurso eletrônico]. Natal: EDUFRN, 2016.

PIACENTI, C. A.; LIMA, J. F. (Org.). Métodos de Análise Regional. 2017.

PERROUX, François. O conceito de pólo de crescimento. Economia regional: textos escolhidos. Belo Horizonte: CEDEPLAR, p. 145-156, 1977. 
RAFFESTIN, C. Por uma geografia do poder. Tradução: Maria Cecília França. São Paulo: Ática, 1993.

ROMER, P. M. Endogenous Technological change. The journal of Political Economy 98 (5), S71- S102. 1990.

ROSTOW, Walt Whitman. Etapas do desenvolvimento econômico: um manifesto nãocomunista. Rio de Janeiro: Zahar, 1974.

SILVA, J. C. C.. A análise de componentes de variação (shift-share). In: COSTA, J. S. (org.) Compêndio de economia regional. Coimbra, Portugal: APDR, 2002.

SILVA FILHO, L. A.; SILVA, F. J. F.; QUEIROZ, S. N. Nordeste industrial: a fragmentação territorial de uma região periférica. Revista Econômica do Nordeste, v. 46, n. 2, p. 9-24, 2015.

SCHWARTZMAN, S. (Org.). Economia Regional - textos escolhidos. Belo Horizonte, CEDEPLAR, 1977. 